\title{
Relationship between Smoking and Concentrations of Some Biochemical Parameters in Blood of Young Smokers
}

\author{
Khalid Shaalan Sahab \\ Department of Chemistry, College of Science, Diyala University, Diyala, Iraq \\ e-mail: khalidshaalan1970@yahoo.com
}

\section{Abstract}

Cigarette smoking is main cause of lung cancer and one of the major causes for cardiovascular problems. Smoking causes changes to some blood contents.

The study aimed to identifying the influence of cigarette smoking on concentrations of glucose, total cholesterol, triglycerides, high density lipoprotein (HDL-C), glucose, low density lipoprotein (LDL-C) and bilirubin in blood of young smokers.

The study conducted among 30 subjects of young smokers and compared with 20 nonsmoker volunteers as control group. The biochemical parameters of blood among all subjects have been determined by using available commercial kits.

The results have been showed that the mean of the total serum bilirubin levels were lower in smokers when compared with controls but with significant $(P>0.05)$. Serum fasting blood glucose (FBG) and total cholesterol (TC) levels were found to be higher in smokers as compared to controls $(P \leq 0.05)$. The comparison between the estimated levels of triglycerides (TG) and low density lipoprotein-c (LDL-C) in smokers and healthy controls subjects showed no significant increased $(P>0.05)$. Also there are no significant decrease in levels of HDL-C in smoking subjects as compared to controls

Conclusion: The conclusion from results, that smoke of cigarette can influence on biochemical parameters such as glucose, total cholesterol and bilirubin in early stages of smoking and produce a problems to cardiovascular system in early ages.

Received: February 3, 2019; Accepted: February 11, 2019

Keywords and phrases: smoking, some biochemical parameters, total serum bilirubin, young smokers.

Copyright (C) 2019 Khalid Shaalan Sahab. This is an open access article distributed under the Creative Commons Attribution License, which permits unrestricted use, distribution, and reproduction in any medium, provided the original work is properly cited. 


\section{Introduction}

Smoking of cigarettes is still highly spread throughout the world although of its dangerous effect on health of human which led to a various of chronic diseases [1]. Smoking is an etiological factor for respiratory diseases, cardiovascular diseases, cancers, and variety of infections [2,3]. Over four thousand compounds are present in smoke of cigarette, and at least 200 compounds from these compounds are toxicant. Some other compounds are known as carcinogenic agents, others are free radical and oxidants which induce oxidative stress by oxidation of lipid and lipoproteins $[1,4]$. These compounds can effect on human organs and its contents of materials and compounds. Blood is a mobile tissue consists of liquid phase "plasma" $55 \%$ which swim in it a solid phase or called "cellular phase" $45 \%$ which include the red blood cells, white blood cells and platelets. Plasma consists of about $90-92 \%$ water, about $7 \%$ proteins, and $1-3 \%$ of other organic and inorganic compounds such as glucose, lipoproteins, urea, uric acid, creatine, creatinine, bilirubin, electrolytes, etc. [5, 6]. The compounds of cigarette smoke when transferring into blood from lungs can react with plasma compounds and change its normal percentage, and also these compounds can arrive into different organs and effect on it $[7,8]$. The changing of normal percentage of plasma compounds may well led to serious dangerous complications [7-11]. Bilirubin is the end product of heme catabolism and the bilirubin in serum has antioxidant property [11, 12]. Several studies have shown that serum bilirubin has a protective effect against cardiovascular disease and decreasing its normal percentage will be with bad effect. Also, the increasing of blood glucose and cholesterol concentrations are contributing agents to vascular problems such as atherosclerosis [11-17].

\section{Materials and Methods}

The study has been done at laboratory of Biochemistry in Chemistry Department, College of Science, Diyala University during the period from February to March 2017. Fifty (50) young male subjects (students) are selected for the study and their ages ranged (from 21 to 25) years. Thirty (30) subjects are smokers and were with duration of smoking for more than 5 years. Twenty (20) healthy non-smoker persons are included in the study as controls and were as smokers in age and BMI.

The samples for assay are taken in the morning from (9-11) A.M., while the smokers and controls are fasting (8-12) hrs. Blood samples are collected by venipuncture, using a 
(10) $\mathrm{ml}$ disposable syringes. The blood samples were transferred into serum separator tube and allowing the blood to clot at room temperature for $30 \mathrm{~min}$ then centrifuged at (4000 rpm) for 5 min. Serum FPG and lipid profile, are measured. Bilirubin has been evaluated by using capillary tube method.

Measurement of Body Mass Index (BMI) was done by using a mathematical formula based on a person's height and weight. BMI is measured by weight in Kilograms divided by height in square meter $(\mathrm{BMI}=\mathrm{Kg} / \mathrm{m} 2)$. Glucose level has been evaluated according to the enzymatic method utilizing a ready-made laboratory kit for this purpose. Also serum total cholesterol, serum triglyceride and high density lipoprotein HDL-cholesterol are determined by utilizing a ready-made laboratory kit for this purpose (commercial enzymatic methods). Low density lipoprotein LDL-cholesterol was calculated according to Friedewald formula.

The data were expressed as mean $\pm \mathrm{SD}$. All of the statistical analyses carried out by using a standard statistical package (SPSS, Chicago, IL, USA). Comparisons of mean values between groups were made by using independent sample $t$ test. A $P \leq 0.05$ was considered significant statistically.

\section{Results}

Subjects were taken for the study after age, BMI, and sex matching. We compared serum total bilirubin, between smokers $(n=30)$ and controls $(n=20)$, the serum total bilirubin levels were lower in smokers when compared with controls but with significant $(P>0.05)$. Serum fasting blood glucose (FBG) and total cholesterol (TC) levels were found to be higher in smokers as compared to controls $(P \leq 0.05)$. The comparison between the estimated levels of triglycerides (TG) and low density lipoproteincholesterol (LDL-C) in smokers and healthy controls subjects showed no significant increase $(P>0.05)$. Also there is no significant decrease in levels of HDL-C in smoking subjects as compared to controls. The above results are shown in Table 1.

\section{Discussion}

From the results we can see the blood glucose is higher in smoker group than nonsmokers group. The compounds of cigarette smoke may reduce the insulin activity to entering the blood glucose into cells or affect the glucose receptor on cell surface which 
Table 1. Comparison of $\mathrm{M} \pm \mathrm{SD}$ for biochemical parameters in the studied groups.

\begin{tabular}{|c|c|c|c|}
\hline Parameter & $\begin{array}{c}\text { Mean } \pm \text { SD } \\
\text { Smokers }(\boldsymbol{n}=\mathbf{3 0})\end{array}$ & $\begin{array}{c}\text { Mean } \pm \text { SD } \\
\text { Non-smokers }(\boldsymbol{n}=\mathbf{2 0})\end{array}$ & $\boldsymbol{P}$-value \\
\hline Age (years) & $22.47 \pm 2.36$ & $22.62 \pm 3.24$ & 0.464 \\
\hline Body mass index (kg/m2) & $21 \pm 2$ & $22.49 \pm 1.21$ & 0.34 \\
\hline TG (mg/dl) & $88.4 \pm 59.7$ & $122.5 \pm 28.7$ & 0.105 \\
\hline TC (mg/dl) & $201.9 \pm 30.5$ & $160.0 \pm 31.6$ & $0.012^{*}$ \\
\hline HDL-C (mg/dl) & $48.4 \pm 14.6$ & $56.9 \pm 17.9$ & 0.15 \\
\hline LDL-C (mg/dl) & $103.2 \pm 25.0$ & $93.3 \pm 36.3$ & 0.25 \\
\hline FBG (mg/dl) & $118.2 \pm 37.9$ & $92.2 \pm 11.0$ & $0.043^{*}$ \\
\hline Total Serum bilirubin (mg/dl) & $0.48 \pm 0.07$ & $0.76 \pm 0.05$ & 0.056 \\
\hline
\end{tabular}

may counteract the insulin activity to entering blood glucose into cells. This result agreed with result of Bornemisza and Suciu who showed that increase of the glycemia after smoking and this result is recorded as a result of presence the nicotine in smoke of cigarette, and reversely, no blood glucose value rises after smoking cigarettes free of nicotine or after smoking but without inhaling the smoke. Nicotine causes an increase in the production of epinephrine and norepinephrine. These hormones are affect the body by increasing blood glucose levels, heart rate, blood pressure, and breathing rate, and also causing the breakdown of lipids and the increase fat levels of blood [18].

The results of lipid profile have been showed there are a non-significant elevation in LDL-C, TG and significant elevation in TC, and there is a non-significant reduction of HDL-C level. These results agreed with results of Devaranavadgi et al. who showed that as the intensity and duration of smoking increases, significant increases are observed in the levels of VLDL-C, LDL-C, TG and TC. And also a significant decreasing in the level of HDL-C is noted in smoker groups as the duration and intensity is increased. These findings add another health enhancing benefit by the cessation of smoking [19].

In the results the level of total bilirubin had been reduced in smoker group as compared to non-smoker group, and these findings agreed with the findings of many previous studies, which noted inverse relationship between smoking and concentration of bilirubin. Bilirubin works as antioxidant in blood and decreasing its level increasing the risk of cardiovascular diseases and stroke [20-23]. 


\section{Conclusion}

The smoking of cigarette in early ages can increase the blood biochemical factors which induce cardiovascular diseases such cholesterol and LDL-C, and reduce the factors that decreasing the cardiovascular diseases such HDL-C or decreasing as antioxidant in blood such as bilirubin.

\section{References}

[1] K. S. Alsalhen and R. D. Abdalsalam, Effect of cigarette smoking on liver functions: a comparative study conducted among smokers and non-smokers male in El-beida City, Libya, International Current Pharmaceutical Journal 3(7) (2014), 291-295.

[2] H. Mehta, K. Nassal and R. T. Sadikot, Cigarette smoking and innate immunity, Inflamm. Res. 57(11) (2008), 497-503.

[3] J. B. Lakier, Smoking and cardiovascular disease, Am. J. Med. 93 (1992), 8-12.

[4] G. L. De Heens, R. Kekkert, L. A. Aarden, U. Van der Velden and B. G. Loos, Effect of smoking on the ex vivo cytokine protection in periodontitis, J. Periodontal Res. 44(1) (2008), 28-34.

[5] William F. Ganong, Review of Medical Physiology, 21th ed., New York: Lange Medical Books/McGraw-Hill, 2003.

[6] Anne Waugh and Allison Grant, Ross and Wilson: Anatomy and Physiology in Health and Illness, 10th ed., Churchill Livingstone Elsevier, 2007.

[7] L. Yildiz, F. Akcay, H. Kaynar and N. Bakan, Increased plasma endothelin-1 in heavy and light smokers, Clin. Chem. 42 (1996), 483-484.

[8] W. Terres, P. Becker and A. Rosenberg, Changes in cardiovascular risk profile during the cessation of smoking, Am. J. Med. 97 (1994), 242-249.

[9] D. Salvemini and R. Botting, Modulation of platelet function by free radicals and freeradical scavengers, Trends Pharmacol. Sci. 14 (1993), 36-42.

[10] B. Frei, T. M. Forte, B. N. Ames and C. E. Cross, Gas phase oxidants of cigarette smoke induce lipid peroxidation and changes in lipoprotein properties in human blood plasma. Protective effects of ascorbic acid, Biochem. J. 277 (1991), 133-138.

[11] C. Mylonas and D. Kouretas, Lipid peroxidation and tissue damage, In Vivo. 13 (1999), 295-309.

[12] H. A. Schwertner, W. G. Jackson and G. Tolan, Association of low serum concentration of bilirubin with increased risk of coronary artery disease, Clin. Chem. 40 (1994), 18-23. 
[13] E. Scheffler, E. Weist, J. Woehrle, I. Otto, I. Schulz, L. Huber et al., Smoking influences the atherogenic potential of low-density lipoprotein, Clin. Investig. 70 (1992), 263-268.

[14] M. Mayer, Association of serum bilirubin concentration with risk of coronary artery disease, Clin. Chem. 46(11) (2000), 1723-1727.

[15] P. N. Hopkins, L. L. Wu, S. C. Hunt, B. C. James, G. M. Vincent and R. R. Williams, Higher serum bilirubin is associated with decreased risk for early familial coronary artery disease, Arterioscler. Thromb. Vasc. Biol. 16 (1996), 250-255.

[16] M. Madhavan, W. A. Wattigney, S. R. Srinivasan and G. S. Berenson, Serum bilirubin distribution and its relation to cardiovascular risk in children and young adults, Atherosclerosis 131 (1997), 107-113.

[17] H. A. Schwertner, Association of smoking and low serum bilirubin antioxidant concentrations, Atherosclerosis 136 (1998), 383-387.

[18] P. Bornemisza and I. Suciu, Effect of cigarette smoking on the blood glucose level in normals and diabetics, Med. Interne. 18(4) (1980), 353-356.

[19] B. B. Devaranavadgi, B. S. Aski, R. T. Kashinath and I. A. Hundekari, Effect of cigarette smoking on blood lipids - a study in Belgaum, Northern Karnataka, India, Global Journal of Medical Research 12(6) (2012), 57-61.

[20] Muhammad Javed Masood, Aamir Ali Khan, Khalid Usman, Humaira Zafar, Zahid Iqbal, Tasneem Zarfishan and Mohi Ud Din Mudassir, Association of smoking and low serum bilirubin antioxidant concentrations, Isra Med. J. 5(3) (2013), 193-194

[21] H. Kimm, J. E. Yun, J. Jo and S. H. Jee, Low serum bilirubin level as an independent predictor of stroke incidence: a prospective study in Korean men and women, Stroke 40(11) (2009), 3422-3427.

[22] J. Jo, H. Kimm, J. E. Yun, K. J. Lee and S. H. Jee, Cigarette smoking and serum bilirubin subtypes in healthy Korean men: the Korea Medical Institute study, J. Prev. Med. Public Health 45(2) (2012), 105-112.

[23] P. G. Hoydonck, E. H. Temme and E. G. Schouten, Serum bilirubin concentration in a Belgian population: the association with smoking status and type of cigarettes, Int. J. Epidemiol. 30(6) (2001), 1465-1472. 